\title{
Application of stem cells in bone repair
}

\author{
Elaine Y. L. Waese • Rita A. Kandel • \\ William L. Stanford
}

Published online: 22 February 2008

(C) ISS 2008

\section{Erratum to: Skeletal Radiol}

\section{DOI 10.1007/s00256-007-0438-8}

Unfortunately, we had indicated the name of the second author incorrectly. The correct name is Rita A. Kandel as now given above.

The online version of the original article can be found at http://dx.doi. org/10.1007/s00256-007-0438-8.

E. Y. L. Waese · W. L. Stanford

Department of Chemical Engineering and Applied Chemistry, University of Toronto,

200 College Street,

Toronto, ON, Canada, M5S 3G9

E. Y. L. Waese $\cdot$ R. A. Kandel $\cdot$ W. L. Stanford $(\bowtie)$

Institute of Biomaterials and Biomedical Engineering,

University of Toronto,

164 College Street,

Toronto, ON, Canada, M5S 3G9

e-mail: william.stanford@utoronto.ca

R. A. Kandel

Department of Pathology and Laboratory Medicine,

Mount Sinai Hospital,

Toronto, ON, Canada 